\title{
Employing Mixed Reality Applications: Customer Experience Perspective
}

\author{
Jani Holopainen \\ University of Helsinki \\ Strategic Marketing and \\ Management \\ jani.m.holopainen@helsinki.fi \\ Essi Pöyry \\ University of Helsinki \\ Consumer Society Research \\ Centre \\ essi.poyry@helsinki.fi
}

\author{
Osmo Mattila \\ University of Helsinki \\ Strategic Marketing and \\ Management \\ osmo.mattila@helsinki.fi
}

\author{
Kaapo Seppälä \\ University of Turku \\ Department of Future \\ Technologies \\ kamise@utu.fi
}

\author{
Petri Parvinen \\ University of Helsinki \\ Strategic Marketing and \\ Management \\ petri.parvinen@helsinki.fi
}

\begin{abstract}
The study analyses twelve empirical cases employing different Mixed Reality (MR) applications: 1) 360videos, 2) augmented reality (AR) mobile applications, 3) augmented virtuality $(A V)$, and 4) $A V+A R$. The empirical data in all cases consist of observations of users' and potential customers' experiences with different MR applications followed by qualitative interviews. The study assesses how various $M R$ applications can create experience-centric services. The research focus is in service and sensory design as well as in customer experience management. The study results suggest that MR can provide new opportunities for prolonged customer experiences in terms of new encounters and cues, different sensory effects and improved social interactions among business representatives and fellow customers. Furthermore, MR experiences can generate positive word-of-mouth especially in cases with dramatic structures. Finally, the results suggest that the customers' willingness-to-interact with service personnel increase after a MR experience.
\end{abstract}

\section{Introduction}

Mixed Reality (MR) technologies are predicted to be a disruptive for human interaction [1]. While the impact of most internet and mobile technologies has been restricted to a limited number of human senses, cognitions and affections, MR technology development is targeting to control all five basic human senses (sight, hearing, taste, smell, touch). It is assumed that the effect on the human mind and emotions will be more complete through total sensory immersion [2,3]. The development of immersive MR technologies that have both a broader and deeper effect on human experiences are opening new interesting research areas in marketing and sales.

MR is a term of a mix of real and virtual environments covering the area between the extrema of the virtuality continuum [4]. At one end of the continuum is a computer-generated virtual environment, virtual reality (VR), without any content from the reality. At the other end is the reality without any virtual content. This broad definition of MR includes applications adding content from the reality to a virtual environment (augmented virtuality, AV) and adding virtual layers to the reality (augmented reality, AR). In this paper, the term MR is used for AR and AV applications, as well as immersive 360-videos [5]. All these technologies can be consumed with head mounted displays (HMDs), while AR is also available with mobile devices such as smartphones and tablets. MR technologies have already been adopted in various business contexts. Some of the most well-known cases include Ford and IKEA, among others, that use MR applications for collaborative design, training and education, B2B sales and marketing, and product showcasing.

The study concentrates on the propositions suggested by Zomerdijk and Voss [6] on designing experience-centric services. Based on these propositions, the research question is: How can various MR environments create experience-centric services? By testing service- and sensory designs as well as the potential of customer-experience management within MR technologies and environments, the study introduces a whole new research vein to the MR field, which has so far concentrated on single technical features and their usability [e.g., 2,3]. Some studies have considered both user experience and sensory effects of different MR technologies and applications [7,8,9]. However, none of these studies considers the full potential of 
service and experience management of MR technologies. We explore the potential of MR in designing experience-centric services by testing six propositions based on experience management, service- and sensory design literatures.

Methodologically, this study explores twelve business cases with early phase MR prototypes aiming to improve their customer experiences. The business contexts applying MR technologies include education, gym, yoga, real estate (two cases), application for disabled people, tourism, construction site planning, interior design, timber sales and advisory services, nature tourism, and industrial training. Each business case applies different MR-generation technologies and environments, which are categorized as follows: 1) immersive 360-videos, 2) AR smartphone and tablet applications, 3) AV, 4) AV+AR. These technologies and environments enable different sensory effects, such as visual 360-experience, sounds, free movability and interaction. The empirical data collected on all business cases is generated by observing and recording users' and customers' experiences with the applications followed by qualitative interviews.

The study offers implications for MR technology and application developers as well as for businesses adopting MR technologies. The MR application field is a potential area for experience-based differentiation as the focus of service and business model design has shifted from addressing functional and technological aspects to user-centric and customer-oriented designs [10]. Central in customer-orientated design are experiments, prototypes and observations of multisensory experience, where tacit, latent and more complex customer requirements can be discovered [10]. These were found to be important also in the case of MR applications for both B2B and B2C companies. For technology developers, on the other hand, it is important to determine, which are the technologies, contents, features and functions that contribute to the total experience, engagement and eventually to the service provider's bottom line.

\section{Research framework}

The proposed research framework combines service design, sensory designs and customerexperience management. Next, six propositions for designing experience-centric services [6] are presented from these perspectives. As there is no research applying these concepts to the MR context, our approach is explorative, testing the potential of MR technologies and environments to create experience-centric services. We first present each proposition and then explain the logic from the literature for analyzing empirical data.
Proposition 1: The design of experience-centric services involves designing a series of service encounters and cues.

While there are multiple factors affecting the customer experience, which is dependent on the context and individual, service-design research [e.g., 10] suggests journeys as monitoring methods for customer experiences. These journeys consisting of several service encounters and cues, that is, touching points, are commonly studied by surveys, interviews, focus groups, and online forums [10]. Well known service-design extensions to contemporary marketing research $[11,12,13]$ suggest that value is co-created by multiple social and economic actors, always including the beneficiary. Furthermore, interaction between a customer and a service provider is the locus of value creation, and both parties can influence the degree of value that is being created [14]. In other words, value is created throughout the customer journey through a series of service encounters and cues.

In the research framework, Proposition 1 represents service design with encounters and cues. Thus, encounters and cues are controlled and analyzed during and after the MR-experience to find out, which ones increase utility the most [15]. As suggested by the literature [14], participants' collaborative ideas, such as ways to improve the MR application or completely new usage innovations, are sought as signs of experience-centric service fulfillment. Similarly, the central idea of commitment is sought through encounters and cues related to the potential benefits of MR technologies, captivating environmental or sensory design details, actual purchase or customer retention behaviors, and word-of-mouth.

Proposition 2: The design of experience-centric services involves sensory design.

Proposition 2 considers the sensory design research [16,17]. The sensory design literature observes different tools and environments affecting sensations including sight, hearing, taste, smell and touch (haptics) and their effects on customer perception, judgment and behavior, for example [18]. The effect of sensory design on customer experience in consumables [e.g., 19] has been found to be the most significant factor for customers' brand experience followed by affective, cognitive and behavioral factors. Especially sight and hearing have been studied in e-commerce by concentrating on user interfaces, usability and visual cues [e.g., 20]. However, multi-sensory experiences, where more than one of the five human senses are exposed, are scarcely researched in marketing or service design literature. In particular, there is no existing research on sensory design that would focus on immersive MR technologies. 
There is some research considering the effects of virtual storytelling [7] and narrative designs on multiple sensory modalities and environmental cues in surgeries [8]. More recently, multi-sensory effects on user experience and performance in virtual environments were researched [9]. The study analyzed the effects of tactile cues, movement wind, directional wind, footstep vibration and footstep sounds. According to the results, tactile cues provided in a virtual space significantly improved the user experience, while footstep vibration improved task performance. In spite of multiple studies in this field, more research is needed in analyzing the sensory effects of MR technologies and applications from customer experience and engagement perspective. In addition, for many of the users, MR is a new sensory environment where they need to learn how to process and perceive information. Therefore, it is suggested that human perceptions in the MR environments can be unexpected and sometimes conflict with usual cognitions in a real environment [1]. This provides a need for explicit research on customers' sensorial experiences in various MR environments.

When considering Proposition 2, the sensory design approach is adopted similarly as in previous ecommerce studies [e.g. 20]. During a MR experience, various effects, such as sight, movability, interaction and sounds are observed as user's emotions and responses $[16,17]$. Similar framework is used to study the feeling of embodiment [2,3] but these studies focus merely on a 'user', not on a 'customer' in a business context.

Proposition 3: The design of experience-centric services involves paying attention to the dramatic structure of events.

The proposition 3 simply combines propositions 1 and 2, suggesting that the fulfillment of experiencecentric services requires combined service and sensory design elements. Theoretically, when service design elements, such as encounters and cues, are coupled with sensory design, dramatic structures of events can emerge $[21,22,6]$. Based on the Proposition 3, we need to understand how service design elements (e.g., encounters and cues) and sensory design (e.g., sight, movability, interaction, sounds) can be merged in different MR environments.

Proposition 4: The design of experience-centric services involves requiring front-line employees to engage with customers.

Proposition 5: The design of experience-centric services involves managing the presence of fellow customers.

Proposition 6: The design of experience-centric services involves closely coupling backstage employees to the frontstage experience.
Propositions 4, 5, and 6 are based on the principles of customer-experience management. The aim of customer experience management is to provide customers a great experience across channels [23]. The main drivers of a customer experience in a retail environment include: social environment, service interface, atmosphere, price, assortment and channels [23]. In addition, prior customer experiences will influence the future customer experience [23]. Otnes et. al [24] highlight social interaction and marketplace rituals as parts of customer experience, while Meyer and Schwager [10] note that customer care, advertising, packaging, features, ease of use and reliability also affect customer experience. Grewal et. al [25] discuss macro-level factors and suggest that a customer experience forms as a combination of promotion, price, merchandise, supply chain and location. Many studies have observed that even small and traditional physical elements such as written documents and marketing and communication materials can play an important role in customer experience [e.g., 26]. Furthermore, it is recognized that personalization, cognitive immersion and physical interaction all affect how customers, together with firms, can co-create their consumption experiences [27]. MR technologies can be seen to have potential to affect all these three elements.

Eventually, human resources management plays a central role in customer experience management [6]. In the research framework, propositions 4-6 aim to capture the potential of MR applications to improve a customer experience by asking: How MR environments can enable front-line employees to engage with customers, how the presence of fellow customers can be managed in MR environments, and how backstage employees can be coupled to the frontstage experience in MR environment?

\section{Method}

In a virtual reality presence and experience studies, both quantitative measures (e.g., arousal, fMRI, or EEG) and qualitative methods (e.g., interviews, questionnaires and open questions) have been applied [28]. Here, the later approaches are employed both to detail respondent experiences and to allow them to express their feelings in a more freeform fashion [29].

In order to assess the different MR generation technologies and environments and their effect on user experience and engagement, we adopt the designscience research approach with qualitative and observation methods introduced by Hevner et al. [30]. The approach produces problem-solving technologybased artifacts, which are evaluated by the researcher to learn from the real-world user experiences [30]. The design-science research is an iterative process where 
different designs are continuously tested and developed to build understanding and guidance to both technology development and business management [31]. Furthermore, the generated designs are tested against requirements and constraints [30].

This study generates and tests different designs against requirements introduced in the theory frame for experience-centric services [6]. Following Hevner et al. [30], these designs are tested with "white box" structural-testing method where user experiences are categorized according to the theory frame ("white boxes") and the in-depth content is sought through a semi-structured interview protocol and qualitative research with data reduction, data display, and drawing and verifying conclusions [32]. The interview protocol was aligned with the research framework to draw potential utility values, encounters and cues and experience-management principles of different MR business cases. In order to record spontaneous emotions and responses, we followed the naturalistic observation method [33]. In addition, we collected socio-demographic information on the participants, including age, gender, education and familiarity with MR technology.

Following the theory frame and the explorative nature of the method, also ideas about the applicability and transferability of different benefits, qualities and attributes were collected. This was done by allowing the participants to describe what actually occurred in each design/artifact to determine whether the described context could be applied to some other cases [34] following the principles of user and design-driven development and innovations $[35,36]$.

\section{Data descriptions}

The study at hand adopts a detailed structure of different business cases with various MR environments, devices and sensory effects introduced in Table 1. Altogether twelve business cases/ artifacts were created and tested among 302 participants. The different MR environments included:

1. 360-videos: Research assistants conducted demonstrations with six different 360-videos at six different sites: 1) gym (rowing machine), 2) real estate business, 3) tourism marketing, 4) yoga (well-being), 5) nature tour service for the disabled, and 6) junior high education. 360-videos do not enable the user to move or interact in the virtual environment. The research assistants implemented test setups by demonstrating their MR-service idea to potential customers by using mobile HMDs (Google cardboard and smartphone) and online 360-degree video content. Altogether 112 user experience interviews were conducted in spring 2016.
2. Augmented reality (AR): Research assistants conducted demonstrations with two different AR apps at two sites: AR furniture and AR houses. The research assistants implemented test setups by demonstrating the AR apps to potential customers by using mobile smartphones (AR furniture) and tablets (AR houses). The furniture application named Sayduck was downloaded from the Google Play Store, while the house application was received from a developer for the research use only. Altogether 40 user experience interviews were conducted in autumn 2016. The artifacts enabled free movement around the augmented object, while the interaction was enabled by placing the virtual objects (e.g., furniture) according to the user's choice.

3. Augmented virtuality (AV): Research assistants conducted demonstrations with a real-life AV prototype. The AV application demonstrated a virtual timber trade/ forest landscape planning, where the user was able to move in a virtual forest and interact by removing and adding trees. The application also demonstrated the income or loss of income from the forest operations. The test setups were implemented by using HTC Vive HMD and demonstrating the application to potential adopters, such as forest sector experts and stakeholders. In autumn 2016, altogether 70 user experience studies were conducted. This application also included realistic 360-photos from forest stands as well as 3D laser-scanned point cloud data visualizations.

For another artifact, research assistants conducted AV demonstrations for real estate showcase, planning and design. This application can be seen to bring solutions to the difficulty of imagining a real house only by seeing leaflets and blueprints. Eventually, the application is hoped to engage customers in designing housing concepts. The application also shows real views from the window of a house even before the house is actually built, and it enables customers to see and participate in designing interiors by making virtual modifications to wall colors, kitchen and bathroom furniture. In addition to providing a 360-experience, the artifact also enables free movement and interactions. Research assistants implemented test setups by using HTC Vive HMD and demonstrated the application to potential apartment buyers at a construction company's showroom. Altogether 20 user experience interviews were conducted in autumn 2016.

The third artifact/business case under this MR environment was nature tourism with 28 tested user experiences. The application allowed movement and interaction with the environment by removing trees from the landscape, for example. A 3D point cloud and 360-degree image were also included. As in all cases 
and in addition to participant interviews, research assistants also observed the behavior of the users.

4. AV+AR: Research assistants conducted demonstrations with a real-life AV+AR application. The application demonstrated a timber harvester with a recorded introduction of its main features. The user was able to listen the introduction and move around the harvester in the AV. The AV test setup was implemented by using HTC Vive HMD. After the AV experience, the same introduction was shown as an AR application with a tablet with the ability to move around the object in reality, and so enabling totally different kind of technology combination. The study sample consisted of potential technology adopters, such as industry experts and stakeholders. Altogether 30 user-experience interviews were conducted in autumn 2016 using the same user sample as for the AV timber trade/ forest landscape planning application.

Table 1. Twelve empirical cases with different MR environments, devices and sensory effects.

\begin{tabular}{|c|c|c|c|c|c|}
\hline Case ID & Business case & $\begin{array}{l}\text { MR } \\
\text { environment }\end{array}$ & MR devices & Sensory effects & $n$ \\
\hline 1) & Education & 360-videos & Cardboard & visual 360-experience & 29 \\
\hline 2) & Gym & 360-videos & Cardboard & visual 360-experience & 19 \\
\hline 3) & Yoga & 360 -videos & Cardboard & $\begin{array}{l}\text { visual } 360 \text {-experience, sounds } \\
\text { (instructions) }\end{array}$ & 14 \\
\hline 4) & Real estate \#1 & 360 -videos & Cardboard & visual 360-experience & 20 \\
\hline 5) & $\begin{array}{l}\text { Application for } \\
\text { disabled people }\end{array}$ & 360 -videos & Cardboard & visual 360-experience & 10 \\
\hline 6) & Tourism & 360-videos & Cardboard & $\begin{array}{l}\text { visual 360-experience, } \\
\text { interaction, sounds (learning } \\
\text { material) }\end{array}$ & 20 \\
\hline 7) & $\begin{array}{l}\text { Construction site } \\
\text { planning }\end{array}$ & $A R$ & Tablets & free movability, interaction & 20 \\
\hline 8) & Interior design & AR & Smartphones & free movability, interaction & 22 \\
\hline 9) & $\begin{array}{l}\text { Timber sales and } \\
\text { advisory services }\end{array}$ & $\begin{array}{l}\text { AV, incl. 360- } \\
\text { images, 3D } \\
\text { point cloud }\end{array}$ & HTC Vive & $\begin{array}{l}\text { visual } 360 \text {-experience, free } \\
\text { movability, interaction }\end{array}$ & 70 \\
\hline 10) & Real estate \#2 & AV & HTC Vive & $\begin{array}{l}\text { visual } 360 \text {-experience, free } \\
\text { movability, interaction }\end{array}$ & 20 \\
\hline 11) & Nature tourism & AV & HTC Vive & $\begin{array}{l}\text { visual } 360 \text {-experience, free } \\
\text { movability }\end{array}$ & 28 \\
\hline 12) & Industrial training & $A V+A R$ & $\begin{array}{l}\text { HTC Vive + } \\
\text { Tablet }\end{array}$ & $\begin{array}{l}\text { visual } 360 \text {-experience, free } \\
\text { movability, interaction, } \\
\text { sounds }\end{array}$ & 30 \\
\hline
\end{tabular}

\section{General results}

In this section, we review the general results of all the different business cases by using the framework of experience-centric service design. On average, the studied MR experiences lasted 3 minutes varying from 2 to 6 minutes, while there seemed to be no variance between the experienced and first-time users. In general, people who were more used to play video games, mainly younger people, used the various application functions and MR environments more by walking around, moving head and arms, peeking, and playing as in a video shooting game (when for example removing trees with a laser beam). This user group was also more demanding and expecting more from the usability and quality of the applications.
Older people and those with less video-game experience were more still and conservative in their movement. Generally, people were slightly suspicious about moving physically in the applications because they were concerned of colliding. Inability to sense physical surroundings created a socially interesting situation, where the users had to trust the system operator (usually a research assistant).

\subsection{Service encounters and cues}

As most of the research subjects participated in the demos in groups, the nature of the service encounters was expected to slightly vary between individuals; some received more upfront information about the experience than others. However, whether the user received a minimal number of cues (e.g., in cases 1-6 by being the first participant in a group) or if it was possible to observe the reactions of others (e.g., by being the last participant in a group) did not seem to affect the degree of surprise the experience generated. Even cues gained by the opportunity to watch a MR experience of another user from the screen of the PC (cases 9 and 12) did not prevent users to be surprised when testing the experience themselves. During the service encounters, the overall atmosphere and mood were very positive. Notably, even if some participants provided ideas for improvement, no one was disappointed. The overall atmosphere and mood in all cases could be described as cheerful, smiling, curious, amazed, positively surprised, and calm. If the users had used MR gears beforehand, they were usually more interested in the production of the applications rather than being surprised by the experience.

During the service encounters, many participants shared ideas for new applications and contexts in which MR could be useful. This seemed to increase the experienced value and engagement towards the service or product. The most innovative ideas (i.e., ideas not provided by anyone else) arose typically from those instances when the participant came from a different field than what the demo application was built for. For example, a participant acting as an electronic company's marketing manager described a process from their business and how it could be visualized in a MR environment. "Realistic models like this could be used in modelling services, for example (company name) service network and its functions. Like modelling a service where some problem is solved by calling to a service desk and then you find the stage of you order. -- Also introducing computer rooms to clients in cases in which a physical access is normally denied". A marketing manager came up with an application idea to their own field: "As we produce building components, this could provide a visualization how all the components look 
together as a building and how it fits to its environment".

\subsection{Sensory design}

360-videos (cases 1-6) provided the least sensorial experiences as the participants were able to only interact with the environment by turning their head. In these cases, the headset was occasionally criticized to be heavy and visibility was mentioned to be poor. Some of the cardboard-device users complained about dizziness. When it comes to MR equipment with better graphics, dizziness was only mentioned by participants who also reported that they have a fear of heights. This indicates that especially the current consumer-level MR technologies are capable of creating a believable, both stereoscopically and emotionally, sense of being in another space. 360videos were occasionally compared to real-world experiences. In comparison, the cases (9 and 11) utilizing content from the reality (e.g., a 360-degree image and point cloud data) only as an additional material benefitted from the connection to reality. This was expressed by the participants when asking detailed questions about the experience. AR cases 7 and 8 did not contain any sound but this was not commented at all by the participants. The combination of a visual experience with a high number of sensorial factors utilized in the application (cases 9, 10 and 12) resulted in the most immersive user experiences.

Case 5 demonstrated a recreational walk in a forest and it was the only case that was mentioned to have benefitted from adding more sensorial factors (smells and free movement). Cases 7, 8 and 12 (AR) offered a possibility to walk around 3D objects. Users of the AR applications were generally less surprised by the experience and concentrated more on the utility aspects of the possible use cases than participants of other demos. Generally, participants of the applications that allowed free movement and interaction with the virtual environment were the most surprised by the experience. The stereoscopic visuals in the VR created a feeling of three-dimensional environment. Despite the simplified graphics, these experiences were generally described to be realistic. Generally, difficulty in using control buttons, heavy or uncomfortable HMDs, inability to see one's own hands, end of the virtual world (grey horizon) were the most often mentioned factors to disturb immersion in the experience. In cases 9 and 11 and 12, immersion was occasionally disturbed as the users were stumbled to the cable connecting a VR headset and a PC. However, as these issues were not dominating the experiences, immersion was deemed successful even in cases that sensually were far from reality. One participant commented on this aspect: "It doesn't necessarily have to look like $100 \%$ real in VR to create an immersion".

\subsection{Dramatic structure of events}

All of the participants, regardless of their tenure with the technology, were fascinated by the technology and thought the experience was immersive. Especially mountains causing realistic feeling of heights and a teleporting function were praised. Overall, dramatic or unusual experiences (such as a bear in case 9) resulted in a high willingness to share the experience with everyone in the room already while using the MR device. The different MR contents and freedoms in sensory levels seemed to affect the dramatic structure of events. In practice this resulted either to passivating or activating the users. Even though the users in cases 1-6 and were fascinated by the new technology, the immersion of some was disturbed by the willingness to be much more active, for example by walking around. Indeed, MR contents with high sensory levels (e.g., walking, teleporting, removing objects) resulted in activating the participant to interact both with the MR content and with the service personnel.

The participants with no previous MR experiences were either interested or skeptical to try the equipment whereas more experienced ones were more eager to get going. In the test setups with the possibility to observe others (cases 2,3 and 6), some participants refused to test the device. In terms of drama, the turning point was clearly when the user put the headset on, especially for the first-time users. Regardless of the participant's initial attitude, reactions were positive. This was expressed by eagerly sharing the experience with the service personnel. Especially in case 9, this was a point for the users to start telling their own ideas on how to use the devices and what might be interesting or beneficial use cases. The experience seemed to be strong and difficult to imagine beforehand even when receiving cues a priori.

\subsection{Front-line employees engaging with customers}

The role of the front-line employees was crucial for the success of the service experience not only because the use of the equipment required guidance but also because of the participants' willingness to immediately share the experience with someone. In all cases, it was the participant who made the first comment after the experience. The more surprised they were about it, the more emotionally loaded the feedback was. The comments were admiring such as "cool experience", "damn it was cool and fun", "This was just great. I wouldn't have believed how far you have developed this!", "very immersive", "this was excellent", "yes, looking good", "very interesting". Especially in the 
technologically more advanced applications, the first comments were usually followed by feedback with deeper analysis of the utilities of the application, proposals for improvements and new use-case ideas. It can be interpreted that the users wanted to return the favor for gaining an interesting and unique experience.

The more sensorial freedoms the applications covered (e.g., free movement and teleportation in cases 9-11), the more difficult it was to use, and the more guidance from the service personnel were needed. It was found that particularly VR headsets created a unique service situation by blocking the visual and audio connections to the real world. This made the participants dependent on the service personnel (making sure the participants do not stumble to a cable or collide with a wall). This unusual social situation made it easy to start a conversation. As the participants generally needed help when using the devices with the most functionalities, the guided use made it possible to naturally make a physical connection with the personnel. Also, as mentioned before, participants' willingness and urge to share ideas and stories from applying MR technologies also underlines the need for documenting the outputs that occur from service personnel engaging with customers using MR technologies.

\subsection{Managing presence of fellow customers}

Managing presence of fellow customers (participants) was found out to be an important factor in designing service encounters. The fellow participants affected the service encounters by offering cues about the experience, co-participated in providing guidance to others, and thereby had an effect on the structure of the events. In cases 1-6, the participating person could only give hints of the content but, in other cases, the non-participating persons were able to get a limited experience through a PC monitor or by watching thorough the screen of an AR tablet. Based on the observations, the presence of fellow participants seemed to affect a given person's user experience surprisingly little; the surprise factor remained the same. In cases 4 and 11, the participants met the service personnel privately and tested the application alone. In terms of experience, no difference compared to the more social service encounters was found. However, the interactions and especially the discussions between fellow customers were not collected.

\subsection{Coupling back-stage employees to the front-stage experience}

The design research method with rapid prototypes offered versatile user experiences and unique service situations especially when VR headsets were utilized.
The socially novel service situation provided an opportunity to collect versatile user-experience data. Further, by utilizing the automated sensory datacollection features of the devices in later iterations of application development, even more in-depth data can be collected. Especially during the first iterations of the service development, qualitative user-experience data is easy to collect and it can be valuable by guiding the service development processes.

In this research, various MR service prototypes were used to observe front-stage experiences. In cases 9 and 12, the application developers coupled directly to the customer experiences by attending the research demos and helping the participants to use the applications. This helped the back-stage employees to better understand especially usability issues. This understanding was utilized in later iterations of application development. However, the applications were rather easy to use and did not require the presence of the developers per se. It was found out that more sales-oriented front-line employees with a basic understanding regarding the technological features of the applications were capable in transmitting the required usability information to the developers by simultaneously concentrating on customer experiences and added value. Besides cases 9 and 12, no further application development was conducted during this research project.

\section{Summary and discussion}

Various MR environments seem to fit well in designing experience-centric services [6]. The results for the research question, how MR technologies and applications can create experience-centric services, can be summarized into three main categories. First, designing longer journeys or chain-of-effects for customers is important [e.g., 10,23]. Here, MR can provide opportunities for prolonged and new kinds of customer experiences in terms of new encounters and cues, different sensory effects and improved social interactions with company representatives and other customers. For example, MR can be applied to a sales process when trying to differentiate from competitors. This study shows that multiple different details in employing MR applications is important: designing the locus for demonstrations, how customers are invited, whether senior managers are present in the demonstrations, whether a salesperson listens to and discusses with customers after the demonstrations. Together with the development of more intuitive user interfaces and more inconspicuous devices, it will be easier for customers to concentrate on the content rather on controls. 
Second, the most successful cases and increased positive word-of-mouth was employed in situations where the MR environment caused something dramatic or unusual: riding a bear or system operator giving a little push when the user was on a cliff etc. In other words, MR applications allow new ways for the company to positively shock the customer [21,22]. Therefore, the companies adopting MR technologies must be venturous and brave in designing MR applications. Compared to any other media in the market, immersion in MR can be reached rapidly simply by putting a headset on. Based on the results of this research, immersion can be easily reached even when surrounded by other people.

Third, designing MR with more sensory effects enabling the customer to move, listen, crouch, move head, and so on, is advised. This creates not only better immersion [2,3], but it also makes the customer to talk more openly during and after the experience. This suggests a new outcome for the customer experience co-creation [11,12,13,27]. In addition, as media consumption has generally become more interactive, technologies that are considered 'modern' may have even higher requirement levels for interaction. Based on the results of this research, MR can be used to increase the level of interaction by enabling a natural dialogue between a customer and a salesperson, which usually proceeds a sales process. This promises MR technologies numerous use cases and possibilities to create radically new kinds of experiences compared to any other media. This research setup did not allow us to study if the window to close a deal was left open, but the results suggest that participants' willingness-tointeract increased after a MR experience. Therefore, it is important for companies using MR applications to design and practice their operations right after the customer stops using the application. By using salesoriented front-line customer employees with basic level knowledge about MR application development, the valuable time of application developers can be saved. Further, front-line customers may be able to concentrate also on the businesses of the customers more deeply. By using sales-oriented front-line employees as intermediaries both sales and application development processes can be accelerated.

\section{References}

[1] Barricelli, B.R., Gadia, D., Rizzi, A. and Marini, D.L.R., "Semiotics of virtual reality as a communication process", Behav. Inf. Technol. 35, 2016, pp. 879-896.

[2] Leonardis, D., Frisoli, A., Barsotti, M., Carrozzino, M. and Bergamasco, M., "Multisensory feedback can enhance embodiment within an enriched virtual walking scenario", Presence Teleoper. Virtual Environ. 23, 2014, pp. 253-266.
[3] Ahn, S.J.G., Bostick, J., Ogle, E., Nowak, K.L., McGillicuddy, K.T. and Bailenson, J.N., "Experiencing Nature: Embodying Animals in Immersive Virtual Environments Increases Inclusion of Nature in Self and Involvement With Nature", Journal of Computer-Mediated Communication, vol. 21, no. 6, 2016, pp. 399-419.

[4] Milgram, P. and Kishino, F., "A taxonomy of mixed reality visual displays", IEICE TRANSACTIONS on Information and Systems, 77(12), 1994, pp.1321-1329.

[5] Saggio, G. and Ferrari, M., New trends in virtual reality visualization of 3D scenarios, Virtual Reality-Human Computer Interaction. InTech. 2012.

[6] Zomerdijk, L.G. and Voss, C.A., "Service design for experience-centric services" J. Serv. Res. 13, 2010, pp.6782.

[7] Papagiannakis, G., Schertenleib, S., O'Kennedy, B., Arevalo-Poizat, M., Magnenat-Thalmann, N., Stoddart, A., and Thalmann, D., "Mixing virtual and real scenes in the site of ancient Pompeii", Comput. Anim. Virtual Worlds 16, 2005, pp.11-24.

[8] Alaraj, A., Charbel, F.T., Birk, D., Tobin, M., Luciano, C., Banerjee, P.P., Rizzi, S., Sorenson, J., Foley, K., Slavin, K. and Roitberg, B., "Role of cranial and spinal virtual and augmented reality simulation using immersive touch modules in neurosurgical training", Neurosurgery 72, 2013, pp. A115-A123.

[9] Feng, M., Dey, A. and Lindeman, R.W, "An initial exploration of a multi-sensory design space: Tactile support for walking in immersive virtual environments, IEEE Symposium on 3D User Interfaces", 3DUI 2016 Proceedings, 2016, pp. 95.

[10] Meyer, C. and Schwager, A., "Understanding customer experience", Harv. Bus. Rev. 85, 2007.

[11] Payne, A.F., Storbacka, K. and Frow, P., "Managing the co-creation of value", Journal of the Academy of Marketing Science, vol. 36, no. 1, 2008, pp. 83-96.

[12] Edvardsson, B., Tronvoll, B. and Gruber, T., "Expanding understanding of service exchange and value co-creation: A social construction approach", Journal of the Academy of Marketing Science, vol. 39, no. 2, 2011, pp. 327-339.

[13] Vargo, S.L. and Lusch, R.F, "Institutions and axioms: an extension and update of service-dominant logic", Journal of the Academy of Marketing Science, 2015, pp. 1-19.

[14] Vargo, S. and Lusch, R., "It's all B2B...and beyond: Toward a systems perspective of the market", Industrial Marketing Management, Vol. 40, Iss. 2, 2011, pp. 181-187.

[15] O'Brien, H.L. and Toms, E.G., "What is user engagement? A conceptual framework for defining user 
engagement with technology”, J. Am. Soc. Inf. Sci. Technol. 59, 2008, pp. 938-955.

[16] Mehrabian, A. and Russell, J.A., An Approach to Environmental Psychology, Cambridge, MA: MIT Press. 1974.

[17] Hoffman, K.D. and Turley, L.W., "Atmospherics, Service Encounters and Consumer Decision Making: An Integrative Perspective," Journal of Marketing Theory \& Practice, 10 (3), 2002, pp. 33-47.

[18] Krishna, A., "An integrative review of sensory marketing: Engaging the senses to affect perception, judgment and behavior", Journal of Consumer Psychology, 22(3), 2012, pp. 332-351.

[19] Brakus, J.J., Schmitt, B.H. and Zarantonello, L., "Brand Experience: What Is It? How Is It Measured? Does It Affect Loyalty?” J. Mark. 73, 2009, pp. 52-68.

[20] Degeratu, A.M., Rangaswamy, A., Wu, J., "Consumer choice behavior in online and traditional supermarkets: The effects of brand name, price, and other search attributes", Int. J. Res. Mark. 17, 2000, pp. 55-78.

[21] Schmitt, B.H., "Experiential Marketing", The Free Press, New York. 1999.

[22] Stuart, F.I. and Tax, S., "Toward an integrative approach to designing service experiences: lessons learned from the theatre", Journal of Operations Management, 22(6), 2004, pp. 609-627.

[23] Verhoef, P.C., Lemon, K.N., Parasuraman, A., Roggeveen, A., Tsiros, M. and Schlesinger, L.A., "Customer Experience Creation: Determinants, Dynamics and Management Strategies”, J. Retail. 85, 2009, pp. 31-41.

[24] Otnes, C.C., Ilhan, B.E. and Kulkarni, A., "The Language of Marketplace Rituals: Implications for Customer Experience Management", J. Retail. 88, 2012, pp. 367-383.

[25] Grewal, D., Levy, M. and Kumar, V., "Customer Experience Management in Retailing: An Organizing Framework", J. Retail. 85, 2009, pp. 1-14.

[26] Ponsignon, F., Klaus, P. and Maull, R.S., "Experience co-creation in financial services: An empirical exploration", J. Serv. Manage. 26, 2015, pp. 295-320.

[27] Minkiewicz, J., Evans, J. and Bridson, K., "How do consumers co-create their experiences? An exploration in the heritage sector", Journal of Marketing Management, Vol. 30 Nos 1/2, 2013, pp. 30-59.

[28] Smyth, M., Benyon, D., McCall, R., O’Neill, S. and Carroll, F., Patterns of Place: An Integrated Approach for the Design and Evaluation of Real and Virtual Environments,
Immersed in Media, Springer International Publishing, 2015, pp. 237-260.

[29] Benyon, D., Smyth, M., O'Neill, S., McCall, R. and Carroll, F., "The place probe: exploring a sense of place in real and virtual environments" Presence, 15(6), 2006, pp. 668-687.

[30] Hevner, A.R., March, S.T., Park, J. and Ram, S., "Design science in information systems research", MIS Quarterly: Management Information Systems, vol. 28, no. 1, 2004, pp. 75-105.

[31] Markus, M. L., Majchrzak, A., and Gasser, L., "A Design Theory for Systems that Support Emergent Knowledge Processes", MIS Quarterly (26:3), 2002, pp. 179-212.

[32] Yin, R.K., Case Study Research Design and Methods, 5th ed., Thousand Oaks, CA: Sage Publications, 2014.

[33] King, S.A., "Researching internet communities: Proposed ethical guidelines for the reporting of results", Information Society, vol. 12, no. 2, 1996, pp. 119-128.

[34] Bogdan, R. C., and Biklen, S. K., Qualitative research for education: An introduction to theories and methods (5th ed.), Boston, MA: Pearson Education Group, 2006.

[35] von Hippel, E., Democratizing Innovation, MIT Press. 2005 .

[36] Verganti, R., "Design, meanings, and radical innovation: A metamodel and a research agenda", J. Prod. Innovation Manage. 25, 2008, pp. 436-456. 